\title{
A PROFISSIONALIDADE DO EDUCADOR SOCIAL FRENTE A REGULAMENTAÇÃO PROFISSIONAL DA EDUCAÇÃO SOCIAL: AS DISPUTAS EM TORNO DO PROJETO DE LEI 5346/2009
}

\author{
LA PROFESIONALIDAD DEL EDUCADOR SOCIAL FRENTE A LA \\ REGULAMENTACIÓN PROFESIONAL DE LA EDUCACIÓN SOCIAL: LAS \\ DISPUTAS ACERCA DEL PROYECTO DE LEY 5346/2009
}

\author{
THE PROFESSIONALISM OF SOCIAL EDUCATOR PROFESSIONAL \\ REGULATION FRONT OF EDUCATION SOCIAL: DISPUTES AROUND THE \\ PROJECT LAW 5346/2009
}

RESUMO: O texto analisa a profissionalidade do educador social frente à regulamentação profissional da educação social imposta pelo Projeto de Lei $\mathrm{n}^{\mathbf{0}}$ 5346/2009. Conceitua educação e educadores sociais, os atores dessa educação e a profissionalidade. Descreve, criticamente, as disputas em torno do citado Projeto, que tramita no Congresso Nacional, e que tem sido alvo de um intenso debate e crítica entre os profissionais da educação social a ponto de muitos desejarem a sua retirada do Congresso pelos equívocos cometidos, por exemplo, permitirá que qualquer outro profissional obtenha registro, sem necessariamente a comprovação tácita e formal de que são educadores sociais, fragilizando dessa forma a construção de uma identidade profissional desse campo educativo. Mas, não há clareza e consenso entre os(as) diversos(as) educadores(as) sociais organizados(as) em associações, como a ABRAPSocial, AEESP e AEC, sobre outras questões, como: a formação mínima para o exercício, se média ou superior, ampliação ou não das áreas de atuação profissional, inclusão da pedagogia social na profissionalidade do(a) educador(a) social, dentre outras. Esse PL já está no segundo substitutivo e, claramente, demonstra a força de decisão de uma das Associações.

PALAVRAS-CHAVE: Educação social. Educador social. Profissionalidade. Regulamentação profissional. Projeto de Lei 5346/09.

RESUMEN: El texto analiza la profesionalidad del educador social frente a la regulamentación profesional de la educación social impuesta por el "Proyecto de Ley $n^{\circ}$ 5346/2009". Presenta conceptos de educación y educadores sociales, los actores de esa educación y la profesionalidad. Describe, críticamente, las disputas acerca de dicho Proyecto, que tramita en el Congreso Nacional, y que ha sido foco de un intenso debate y crítica entre los profesionales de la educación social hasta que muchos deseen sacarlo del Congreso por los equívocos realizados, por ejemplo, permitirá que

\footnotetext{
${ }^{1}$ Dr. em Educação/UFBA, líder do Grupo de Pesquisa em Educação Social, Currículo e Formação do Educador (GESCFORME), pesquisador do Grupo de Pedagogia Social/USP e membro do Comité de Ética e Pesquisa em Seres Humanos - CEP/UNEB. Prof. do Departamento de Educação - Campus Universidade do Estado da Bahia (UNEB). Prof. do Programa de Pós-graduação em Educação de Jovens e Adultos (MPEJA), Departamento de Educação I, Universidade do Estado da Bahia (UNEB) Email: antonyopereira@yahoo.com.br
} 
cualquier otro profesional obtenga registro, sin necesariamente la comprobación legal y formal de que son educadores sociales, fragilizando de ese modo la construcción de una identidad profesional de ese campo educativo. Pero, no está claro y no hay consenso entre los(las) diversos(as) educadores(as) sociales organizados(as) en asociaciones, como la ABRAPSocial, AEESP e AEC, sobre otras cuestiones, como: la formación mínima para esa actividad profesional, se debe ser secundaria o superior, ampliación o no de las áreas de actuación profesional, inclusión de la pedagogía social en la profesionalidad del(la) educador(a) social, entre otras. Ese Proyecto de Ley ya está en el segundo sustitutivo y, claramente, demuestra la fuerza de decisión de una de las Asociaciones.

PALABRAS CLAVE: Educación social. Educador social. Profesionalidad. Regulamentación profesional. Proyecto de Ley 5346/09.

ABSTRACT: The text analyzes the professionalism of the social educator front profissonal regulation of social education imposed by the Draft Law No. 5346/2009. Conceptualizes education and educators, actors such education and professionalism. Describes critically the dispute surrounding the said Project, which the National Congress, which has been the subject of intense debate and criticism among practitioners of social education so that many wish his retirement from Congress by misconceptions perpetrated by example, allow any other professional obtains registration, without necessarily proving tacit and formal educators who are handicapping thus building a professional identity that educational field. But, there is clarity and consensus among (the) many (as) teachers (as) organized social associations, as ABRAPSocial, AEESP and AEC, on other issues, such as the minimum qualification for the exercise if average or higher, amplicon or not the areas of professional activity, inclusion of social pedagogy in the professionalism of the (a) educator (a), amongst others. This PL is already the second replacement, and clearly, showing the strength of a decision of the Associations.

KEYWORDS: Social education. Social educator. Professionalism. Professional regulation. Project Law 5346/09.

\section{Introdução}

A educação social é um campo de conhecimento teórico-prático, multirreferencial, situado em contextos sociais concretos e agregador de práticas educativas, algumas estruturadas, outras em fase de estruturação, como a educação de rua, educação prisional, educação de pessoas trabalhadoras do sexo, educação comunitária, dentre outras. A ciência dessa educação é chamada de Pedagogia Social, que busca sistematizar essas práticas educativas, teorizando-as, explicitando as suas contradições, avanços e retrocessos epistemológicos, evidenciando as suas finalidades sociais, políticas e ideológicas. 
É uma educação que procura atender todos aqueles que estão ou se encontram em processo de exclusão social, conhecidos como vulneráveis, assistidos, desfiliados. O profissional dessas práticas é o (a) educador(a) social, que trabalha para a integração social desses sujeitos, mudando o quadro de marginalização a partir de uma ação social e pedagógica eficiente. Sua presença sempre foi marcante no enfrentamento das questões sociais do país, com diversas denominações, ora como trabalhador social, ora como educador popular, sempre à frente de trabalhos com crianças, adolescentes, jovens, adultos, velhos, trabalhando ora para o Estado, a igreja, os movimentos sociais, as ONGs.

Entre os anos de 1980-1990 esse profissional começou a ter visibilidade social por conta da abertura política que possibilitou, aos poucos, a publicização de muitos problemas históricos, como por exemplo, o extermínio de crianças e adolescentes pobres, que viviam nas ruas das principais capitais do país, defendendo o direito à vida do grupo vitimado. Essa atuação não exigia uma formação ampla, apenas um desejo de mudança nas condições de vida desse grupo em processo de extermínio, geralmente ele trabalhava com o apoio de outros profissionais, como psicólogos, assistentes sociais, sociólogos, e formava uma rede solidária de ação pedagógica, social e política no enfrentamento dos problemas das populações marginalizadas.

Hoje, com a diversificação do trabalho social, há uma necessidade imperiosa de profissionalizar o(a) educador(a), com uma formação crítica e pelo reconhecimento legal da profissão de educação social, o que já vem ocorrendo a partir do Projeto de Lei(PL) no 5346/2009. O diálogo será entre a profissionalidade, a formação e a regulamentação, expondo as disputas em torno do Projeto de Lei, bem como seus impactos para a atividade de trabalho do educador. Nesse aspecto, primeiro vamos revisitar o conceito e o contexto histórico da educação-pedagogia social, dos seus atores sociais, do (a) educador (a) social e sua profissionalidade; em seguida, desvelar as (in) tenções, contradições, equívocos e relações de poder no processo de regulamentação profissional da educação social.

\section{Educação-pedagogia social e seus atores sociais}

Ratificando, a educação social se define como uma prática educativa que busca a integração dos diversos indivíduos e grupos marginalizados, lutando para que estes sejam considerados como sujeitos de direitos; portanto, uma educação que está, 
concomitantemente, dentro e fora dos muros da escola, que pertence tanto ao campo das práticas pedagógicas formais, como não formais, sem deixar de sensibilizar-se pelas informais. Concebemos que essa educação é o campo onde as práticas se fazem presentes e a pedagogia social, como ciência dessas práticas, busca estudá-las, ao mesmo tempo, fornece-lhes possibilidades didáticas para a sua concretização.

Para Caliman (2011, p. 245 - grifo nosso), a pedagogia social é "uma ciência normativa, descritiva, que orienta a prática sociopedagógica voltada para indivíduo ou grupo que precisam de apoio e ajuda em suas necessidades [...]”. E a educação social, segundo Loureiro e Casteleiro (2009, p.88), “[...] constitui a ação, um espaço de intervenção pública [...]”, que, segundo Silva (2011, p. 188), refere-se tanto à "[...] educabilidade social do indivíduo", como à "[...] educabilidade da família, da comunidade, da sociedade, dos governos, do Estado e de suas instituições.”. Para Érico Machado, (2012, p. 4), a educação social são práticas transformadoras que “[...] não seguem a didática escolar, no sentido de apenas transmitir conteúdos. Assumindo a concepção de construção de conhecimento, transformação da realidade e a emancipação através da conscientização crítica dos fatos do cotidiano [...]”.

Os sujeitos dessa educação são todos aqueles que já perderam ou estão em vias de perder sua identidade social e que se sentem incapazes de lutar sozinhos contra as condições materiais apresentadas, chamados de vulneráveis ou desfiliados socialmente. O que significa dizer, segundo Castel (1994; 1997; 1998), que eles estão em uma zona de intermediação entre a inclusão e a exclusão ou que já estão totalmente excluídos. Para esse autor, a vulnerabilidade ocorre sob dois ângulos: o da ausência ou não de integração e da inserção dos indivíduos, respectivamente, no mundo do trabalho e no mundo social e familiar. Às vezes, os indivíduos podem estar integrados no trabalho, mas não inseridos em um grupo familiar por diversas questões.

Desses dois ângulos surgem quatro zonas com atributos sociais definidos: integração, quando o indivíduo faz parte do mundo social e produtivamente de maneira igualitária, sem sofrer arreveses; vulnerabilização quando o indivíduo participa tanto precária como fragilmente do mundo do trabalho e social; desfiliação quando não participa de ambos os mundos, está totalmente excluído e, por fim, os assistidos, que são aqueles que não têm condições de trabalhar, mas são amparados por alguma política pública e pela sociedade civil organizada.

Nesse sentido, podemos pensar, a partir de Castel, sobre a finalidade da educação 
social que seria não deixar que os indivíduos adentrem as zonas inferiores, ao contrário, fazer com que eles cheguem à zona de integração. Essa educação atuaria nos espaços para ressocializar esses indivíduos na busca de sua emancipação social.

Nesse contexto, a ressocialização encerra diversos campos de atuação, seja o psicológico, o político, o ideológico, e tantos outros, mas também o pedagógico, pois, para ressocializar um indivíduo, são necessárias diversas ações capazes de promovê-lo social e cognitivamente. É bom afirmar que ressocializar não é socializar novamente pelo ensino de normas e padrões sociais, mesmo porque essas pessoas continuam sociais, participando da sociedade, porém de maneira marginal, há que se dizer também que não se deixa de ser um ser social, ontologicamente falando. Nesse caso, ressocializar é um termo equivocado, mas que, por falta de outro mais apropriado, o campo da educação social se apropriou, resguardando, no entanto, as críticas necessárias ao termo.

Ressocializar é diferente da docência; espelha-se nesta, mas se distancia por não centrar suas ações educativas no ensino convencional de conteúdos. O que há de pedagógico no ressocializar é do âmbito da educação social. Aqui, vale pensar que esse pedagógico deve ser social, o pedagógico social, ou seja, demandas sociais que requeiram conhecimentos, ações e atitudes da pedagogia social, com o claro objetivo de promover a mudança radical na vida de pessoas e grupos em situação de vulnerabilidade e desfiliamento social. Esse pedagógico está mais próximo da concepção freireana de conscientizar/conscientização que significa mudança radical das condições (i) materiais dessas pessoas e grupos.

Isso significa dizer que a educação social tem um quefazer, freireanamente falando, devido ao solo contraditório do capitalismo que, a cada dia, coloca desafios em vários campos da vida social para os quais urge buscar soluções. E aqui está a questão umbilical dessa educação: ela é uma ação para transformar as condições (i) materiais impostas pelo capital, ou apenas representa, como muitas outras, ações educativas paliativas de conformação de tais condições opressoras? Vale questionar, aqui, se quando essa educação trabalha na zona da integração, não estaria assumindo a condição de uma prática de conformação? Nesse caso, é sempre bom trazer para essas análises a crítica marxista, em particular, o pensamento de Mészáros (2005), quando defende uma educação para além do capital.

Claro que o julgamento crítico da educação social deve ser a partir de um estudo aprofundado que aponte, concretamente, os caminhos epistemológicos, pedagógicos e 
ideológicos que tem seguido. Também será de bom tom definir o significado de emancipação e de integração que a prática assumiu nessa caminhada.

Tais definições são basilares também para identificar se essa pedagogia ainda guarda resquício histórico com algum modelo de pedagogia social, seja com aquelas nascidas na Alemanha, pelas mãos de Karl Magwer, Diesterweg e Nartop, com forte influência de Pestalozzi e Froebel, seja aquelas mais críticas influenciadas pelo marxismo. Caliman $(2010,2011)$ identifica algumas concepções de pedagogia social desde o seu nascedouro até os tempos atuais, são elas: a) como teoria da educação geral, já que toda educação é social, b) como educação política e nacionalista de formação da juventude para adaptar-se aos determinantes sociais, c) como ação que viabiliza a participação coletiva na sociedade a partir da socialização de todos, para todos, d) como educação para a prevenção social. Em vários países da Europa é uma educação que nasce vinculada aos problemas da revolução industrial, como sinaliza López (2009), exceto na Espanha que nasce no final do século XIX e início do século XX para atender a infância e adolescência em situação de risco social, mas com forte influência da pedagogia social alemã, devido às muitas publicações ocorridas na Espanha.

Esse fenômeno que possibilitou o desenvolvimento intelectual da pedagogia social nesse país-é muito parecido com o vem acontecendo no Brasil, pois essa pedagogia chega pelas mãos dos meninos e meninas em situação de rua, nos anos de 1980 - 1990, com a chamada pedagogia social de rua, segundo Pereira (2009), embora alguns educadores afirmem se tratar de um tipo de educação popular, e vai assumindo outras populações vulnerabilizadas socialmente. No nosso contexto social, político e educativo assume a práxis como possibilidade de mudança radical da vida de pessoas excluídas a partir das ideias do educador Paulo Freire. Alguns estudos, como os de Stela Graciani (2001), Oliveira (2004), Pereira (2009), Paiva (2010) e outros, buscavam dar conta de sistematizar a pedagogia social voltada para as crianças e adolescentes em situação de risco, efetivamente no contexto da práxis, porque havia uma crença, que ainda hoje permanece inabalável, de que a articulação teoria e prática educativa e um forte aparato de assistência social seria o caminho para a emancipação dos meninos(as) de rua.

\section{O (a) educador (a) social e sua profissionalidade}

O profissional responsável pela condução da práxis nas práticas educativas sociais é o (a) educador(a) social, que hoje é reconhecido social e profissionalmente, diferente 
do passado, quando a educação social sequer era (re)conhecida nos meios educacionais do país. A grande vedete, aqui, era a educação popular, que assumia as possibilidades de práticas educativas diversas, e o (a) educador(a) era uma figura discriminada, porque assistia aquelas populações marginalizadas, era invisível profissionalmente, nem mesmo lhe era dado o nome de educador(a), mas de trabalhador social.

Segundo Donzelot (1986), o trabalhador social, no início dos anos de 1900, tinha a difícil tarefa de civilizar as crianças e adolescentes, que possuíam comportamento fora do padrão estabelecido, intervindo com práticas educativas corretivas do comportamento. Esse profissional foi institucionalizado quando o Estado passa a assumir a infância e a adolescência tida como problemática. É a época em que a fase caritativa e filantrópica sai de cena, as instituições totais começam a se proliferar em todo o território nacional, a partir da Fundação Nacional do Bem-estar do Menor (FUNABEM), nos anos de 1960, exigindo um tipo de profissional que atuasse no corpo a corpo com as crianças e adolescentes indesejados socialmente.

As muitas entidades de assistência ao menor criadas no Brasil representaram a expressão máxima da ideia de instituições totais, assumindo a função de depósito de adolescentes tidos como inadaptáveis ao convívio social, sob a vigília implacável do grupo de controle que, em vez de proteger a integridade física, psíquica e moral, utiliza todo tipo de violência, de simbólica à física, para a perda da identidade social trazida. Esse tem sido o papel das instituições totais que, segundo Goffman (2008, p. 22), "são as estufas para mudar pessoas", lugar de neutralização do eu social e do eu particular, de maneira que a pessoa seja estranha a si, perdendo a própria imagem de si, ficando desprotegida e mais acessível ao profanamento da instituição.

O papel do trabalhador social no âmbito dessas instituições era o de manter a ordem vigente a todo custo e isso explica a construção preconceituosa em torno desses profissionais. Vale lembrar que, em Paulo Freire (1983), encontramos atributos do trabalhador social, próximo do que hoje defendemos para o (a) educador (a): aquele (a) capaz de possibilitar a conscientização crítica dos oprimidos. Freire (1983, p. 60 - grifo do autor), portanto, politiza as ações desse trabalhador, afirma sua importância na sociedade e lhe atribui aquela que será a marca de sua profissionalidade quando diz: “[...] tentar a conscientização dos indivíduos com quem se trabalha, enquanto com eles também se conscientiza, este e não outro nos parece ser o papel do trabalhador social que optou pela mudança".

Essa mudança proposta na educação popular e que, portanto, exigia educadores 
populares emancipadores, comprometidos com os oprimidos, foi o elemento presente quando da institucionalização do profissional da educação social no final dos anos de 1970 e início dos anos de 1980, no processo da abertura política nacional. O último processo veio dar ao educador social a notoriedade necessária durante o enfrentamento das questões sociais, envolvendo meninos e meninas pobres que viviam nas ruas e eram vítimas de extermínios coletivos.

É esse profissional que, trazendo as experiências tácitas e formais do trabalho social e da educação popular, agora vai também construir outra possibilidade de atuação para enfrentar os problemas de grupos em situação de vulnerabilidade social. Isso ocorre, segundo Pereira (2011), porque, na abertura política, coexistem vários movimentos sociais em prol da infância e adolescência marginalizada, culminando em várias ações e encontros. Um dos mais importantes foi o I Seminário Latino-americano sobre Alternativas Comunitárias para Meninos de Rua, em 1984, na cidade de Brasília. Esse seminário defendeu outra concepção de assistência e educação, que não a corretiva e repressora. Formou-se, então, uma rede política solidária a favor da infância perdida, culminando na construção de um movimento social a favor dos meninos e meninas de rua, chamado de Movimento Nacional de Meninos e Meninas de Rua (MNMMR), que agregou educadores sociais, políticos e pessoas da sociedade civil.

Foi nesse período que o termo educador/a social adquiriu legitimidade profissional nos trabalhos realizados pelas organizações governamentais e não governamentais, tendo uma notoriedade maior na prática de educadores sociais, como Antônio Carlos Gomes da Costa, na FEBEM-MG, Stela Graciani, no Núcleo de Trabalho Comunitário (NTC), da Pontífice Universidade Católica de São Paulo (PUC-SP), Cesare La Rocca, do Projeto Axé, em Salvador. Esses e outros educadores sociais foram os agentes da linha de frente que operariam mudanças necessárias na vida de crianças e adolescentes vulnerabilizados, a ponto de contribuírem, decisivamente, na institucionalização do Estatuto da Criança e do Adolescente nos anos de 1990.

Nos anos 2000, são formadas as principais associações de educadores sociais com o objetivo de legitimar as ações de trabalho desse profissional. A primeira foi a Associação dos Educadores e Educadoras do Estado do Ceará (AESC), em 2004. Outras surgiram em vários Estados da federação, como a Associação dos Educadores e Educadoras Sociais do Estado de São Paulo (AEESP), Associação Estadual dos Educadores Sociais do PETI - Bahia (AMOPETI). Essas instituições, de alguma forma, estão lutando, politicamente, para que a profissão seja reconhecida pelo poder público e 
pela sociedade civil, e esse também tem sido o papel de instituições que buscam legitimar a pedagogia social no país; é o caso da Associação Brasileira de Pedagogia Social (ABRAPSocial), sediada em São Paulo.

A profissionalidade do (a) educador (a) social nasce atrelada aos problemas da infância e adolescência, mas não se resumia a esse grupo, passando a trabalhar com diversos outros, desde que fossem considerados excluídos. Nesse sentido, o centro da sua profissionalidade é a situação (i) material opressora, injusta dos indivíduos e grupo atendidos por ele/ela, que requer uma atuação educativa crítica e no contexto de políticas públicas solucionadoras dessas situações. É na atuação que o(a) educador(a) social vai construindo sua profissionalidade, adquirindo competências, desenvolvendo habilidades, construindo saberes sobre a sua prática.

Quando falamos da profissionalidade do educador social, partimos da mesma referência teórica e prática da profissionalidade docente, como Sacristán (1991), Tardif, Lessard e Gauthier (2001), Contreras (2002), dentre outros.

Para Sacristán (1991), a profissionalidade docente trata-se de certas especificidades existentes no trabalho do professor, exclusivo dessa profissão, não vista em nenhuma outra, que nada mais é do que o saber sobre a ação educativa, a atitude em resolver nessa ação-educação os problemas que dela advenham. É a reflexão dessa ação para nova tomada de atitude, conferindo ao docente o desenvolvimento de competências e capacidades da e para a docência. Segundo Contreras (2002), todas as profissões se articulam em torno de algum saber teórico e prático, autorregulando-se com o objetivo de construir uma identidade própria à atividade profissional, o que não é diferente com a profissão docente. Para Tardif, Lessard e Gauthier (2001), a profissionalidade é a construção, na prática, das experiências, dos saberes e conhecimentos da docência e tudo o que diz respeito a esta nas suas relações mais amplas.

No caso do educador social, sua profissionalidade também gira em torno de saberes sobre o fazer e o pensar determinado pela reflexão da prática educativa, que o qualifica para uma atuação transformadora, desenvolvendo nele competências psicofísicas, como, por exemplo, a capacidade de análise e crítica da realidade dos atores sociais que ele atende, ou ainda a capacidade de autonomização permanente em relação a sua prática, aos atores, aos agentes públicos e privados que articulam políticas de proteção, aos colegas de profissão, dentre outros.

Essa profissionalidade é pautada na autoria da prática porque o(a) educador(a) inventa e reinventa ações educativas e ressignifica teorias pedagógicas no processo da 
ressocialização e da promoção cognitiva e social das pessoas vulnerabilizadas e desfiliadas. Há de se falar, que muitas práticas existentes ainda não têm registros de suas ações, outras estão em fase de estruturação pedagógica, se delineando na teia social, algumas sequer existem no mundo concreto, mas sim no pensamento, como possibilidade de vir a ser, existir; outras ainda estão envoltas em preconceitos e discriminações que sem a quebra dessas representações, não há como sistematizá-las.

É na atuação diária que esse profissional vai se constituindo e legitimando a sua profissão, ou, como prefere dizer Graciani (2001, p. 205), construindo-se ativo e criativamente a partir de "[...] um novo referencial teórico integrado, organizado e coerente, no processo dialético trabalhoso e permanente da construção/desconstrução, inclusão/exclusão, sempre em busca das leis universais da vida”. Para tanto, ele precisa ser um investigador da educação que concretiza, observar tudo a sua volta, os educandos, a situação deles, seus sentimentos, perceber as contradições e partilhar as oportunidades.

E é essa conscientização investigadora que deve pautar suas atividades pedagógicas, desenhando, como defende Gohn (2010, p. 54), “[...] cenários futuros; os diagnósticos servem para localizar o presente, mas também para estimular imagens e representações sobre o futuro. O futuro como possibilidade é uma força que alavanca mentes e corações, impulsiona para a busca de mudanças". Gohn (2010, p. 52) ainda afirma que o trabalho do educador social é de construção de "[...] cidadania no território onde atua", de costura de um "[..] tecido social novo em que novas figuras de promoção da cidadania poderão surgir e se desenvolver".

Cada modelo de educação social exige um tipo de educador (a) com formação específica, isso compreende não apenas a escolarização básica e superior, mas, sobretudo, a qualificação profissional imbricada na reflexão da sua prática educativa. Para isso é essencial a construção de um currículo que agrega as possibilidades de atuação, em uma perspectiva crítica e mobilizadora.

Esse currículo deve explicitar questionamentos do tipo: O que é conhecimento pedagógico e social? A quais conhecimentos o educador social deve ter acesso? Para que e como? As respostas a essas e outras questões dependem da participação ativa daqueles que estão, efetivamente, atuando na área por saberem do tipo de formação que precisam, levando em consideração a sua profissionalidade na formulação desse currículo já que as demandas por educadores (as) sociais, em diversas áreas, são inquestionáveis. Haja vista a crescente demanda das creches; das comunidades 
indígenas, quilombolas; dos grupos de riscos, das pessoas hospitalizadas com HIV, das crianças e adolescentes hospitalizadas vítimas do câncer; dos movimentos sociais em prol da moradia, da terra, dos atingidos por barragens, dentre outros.

Defender uma formação que seja, ao mesmo tempo, centrada e multirreferencial, não significa ecletismo epistemológico, justaposição de conhecimentos, mas uma atitude integrada de leitura do mundo, como advoga Freire (1997). Pensar nessa integração de maneira crítica e contextualizada no currículo é a primeira condição para se negar a formação desse profissional, baseada na polivalência que visa um profissional que assuma multifunções em organizações governamentais e nãogovernamentais, pois as muitas funções e tarefas, necessariamente, não representam a intelectualização da força de trabalho do (a) educador (a) social.

Nesse contexto, a regulamentação da profissão de educação social vai impactar diretamente no mercado de trabalho e na valorização desse trabalhador, quando da obrigatoriedade da aquisição de conhecimentos e saberes que potencializará as habilidades e competências para o trabalho social, aumentando o nível de exigência na contratação desse profissional e os ganhos salariais. Lembrando que não são apenas as organizações não governamentais que contratam, empresas em vários ramos, sensíveis ao social, também têm ampliado suas ofertas de emprego.

\section{A regulamentação da atividade de trabalho do educador social: o projeto de Lei $\mathbf{n}^{\circ}$ $5346 / 2009$}

Os impactos da regulamentação também recairão sobre o campo de atuação que será legitimado, qual seja, pedagógico social - lugar de disputa de outras profissões pedagógicas, porque, subjacentemente, existem várias práticas de educação social, que defendem atributos diferenciados para os seus profissionais e que, necessariamente, não são chamados de educadores sociais. Mas não podemos negar que existe um esforço de agregar todos os profissionais que trabalham com o social educativo na categoria de educador (a) social, desde que seja na atividade de ressocialização.

Essa regulamentação compreende não apenas os aspectos pedagógicos, mas os da assistência social, o que torna a profissão de educação social ética e socialmente útil, economicamente necessária ao mundo do trabalho. Sabemos que uma profissão, para ser regulamentada, precisa ter um lastro econômico e social. O econômico é quando o mercado precisa de um tipo de trabalhador que execute determinada atividade para a 
produção de uma mercadoria útil, negociável e lucrativa; o reconhecimento de que esse trabalhador executa uma atividade necessária para a sociedade, é chamado de social. E dentro desse contexto, a educação social, ao trabalhar com as questões de inadaptação social, é vista como salvadora da pátria porque busca a promoção social, cognitiva, afetiva de pessoas inadaptadas, sanando ou amenizando muitas questões sociais que atingem a todos.

É importante dizer que, independentemente do lastro da profissão, todas se articulam em torno de determinados conhecimentos e experiências que constroem a identidade profissional do trabalhador. Essa, por sua vez, é considerada a partir de uma regulamentação que, segundo Diniz (2001) e Dubar (2005), ampara-se em um conjunto formal de competências e habilidades do trabalhador que deve obedecer a um código de ética capaz de respaldar as suas ações de trabalho, que lhes dá o respeito social necessário.

A disputa pela regulamentação profissional é originada da movimentação de um grupo interessado pela sua atividade de trabalho que exige, legalmente, o controle dessa atividade e das competências do profissional pelo Estado e mercado; portanto, é um requisito adaptativo ao mundo do trabalho, é uma forma de impedir o exercício profissional de pessoas sem a qualificação necessária, pois quando se freia a entrada de outros trabalhadores, pela afirmação da lei e da formação escolarizada, afirma-se o direito pela exclusão e o status profissional pela corporação. Nesse sentido, temos a clareza de que, quando defendemos a legalização da profissão de educação social, estamos querendo a regulação pelo Estado capitalista das atividades de trabalho e das competências profissionalizantes, bem como das regras e condutas do(a) profissional educador(a) social.

É nesse viés que vem sendo discutida essa profissão em várias partes do mundo, desde os anos 1990/2000, haja vista os diversos documentos que comprovam isso quando elaborados nos muitos encontros de educadores sociais como, por exemplo, a Declaração de New York de 1990, a Declaração de Barcelona em 2003, a Declaração de Montevidéu em 2005 e a Carta de Pedagogia Social em 2006. Todas elas instituindo/legitimando compromissos com essa profissão, sem falar nas muitas legislações, como o Código Deontológico da Profissão de Educador Social de Portugal, elaborado em 2001. (SOUZA NETO; SILVA; MOURA, 2009)

No Brasil, essa ideia existe há muito tempo, mas só recentemente há um posicionamento concreto e legal, primeiro com a inserção de atributos profissionais do 
(a) educador(a) social na Classificação Brasileira de Profissões, do Ministério do Trabalho e Emprego, em 2009, sob o número 5153-05, afirma que o exercício dessa profissão visa "garantir a atenção, defesa e proteção a pessoas em situações de risco pessoal e social. Procuram assegurar seus direitos, abordando-as, sensibilizando-as, identificando suas necessidades e demandas e desenvolvendo atividades e tratamento". (BRASIL, 2011) E segundo, com o Projeto de Lei (PL) n ${ }^{\circ} 5346 / 2009$, do deputado Chico Lopes, do Partido Comunista do Brasil, do estado do Ceará, que dispõe sobre a criação da profissão de educador/a social. (BRASIL, 2012)

Esse Projeto propõe regulamentar as atribuições cognitivas e sociais do(a) educador(a) social, de maneira magistral e incontestável, como fica claro no Art. $1^{\text {o }}$, Parágrafo único, quando diz que "a profissão que trata o caput deste artigo possui caráter pedagógico e social, devendo estar relacionada à realização de ações afirmativas, mediadoras e formativas". Observemos que, diante dessa afirmação, não há porque ser contra essa regulamentação, embora o Parágrafo Único esteja incompleto por não definir o que é o pedagógico e social para essa profissão, já que outras também anelam por esses campos, o que pode gerar conflitos futuros com outras profissões.

No Art. $2^{\circ}$ do citado projeto, fica evidente o caráter formativo, a profissionalidade e o campo de atuação desse profissional, sendo determinado que seja nos espaços não formais da educação. Aqui, existe uma omissão quando desconsidera os espaços formais como lugar de atuação, pois também aí existem pessoas em situação de vulnerabilidade/desfiliamento social. Por exemplo, a escola é lugar, infelizmente, de exclusão de toda ordem e precisa de um profissional sensível a essas ocorrências. Esse Art. também identifica os sujeitos que devem ser atendidos pela ação educativa desse profissional, que seriam aquelas pessoas e grupos em situação de vulnerabilidade social, emocional, racial, discriminatória, dentre outras. (BRASIL, 2012).

O Art. $3^{\circ}$ determina que a formação mínima exigida para atuar como educador (a) social deva ser ensino médio, não prevê a possibilidade de uma formação profissional, de nível médio em educação social, bem como uma graduação em pedagogia social legitimadora de uma carreira profissional. No Art. $4^{\circ}$, estipula que o poder público crie cargos e funções de educação social e que a admissão deva ser de acordo com a formação. (BRASIL, 2012).

Esse PL, quando chegou à Comissão de Trabalho, de Administração e Serviço Público (CTASP), foi considerado, pelo deputado Assis Melo, relevante, mas equivocado formalmente em alguns aspectos, como: não considera que uma profissão 
não é criada pelo Estado, mas pela necessidade social, que o Estado apenas regulamenta o que já existe para fins de proteção social e que não cabe ao Ministério da Educação elaborar e regulamentar políticas de formação para o exercício dessa profissão, mas ao poder executivo, assim como também a criação de cargos públicos na área, bem como plano de carreira e salário são da alçada dos Estados e Municípios, não podendo, dessa forma, quebrar o pacto federativo constitucionalmente garantido.

Diante disso, a CTASP propôs um primeiro substitutivo (SBT 1 - CTASP) ao Projeto de Lei 5346/09 que julgamos ser um desmonte, quando desconsidera: a) parte do Art. $2^{\circ}$, nos incisos XI, XII, XIII E XIV, respectivamente, no trato da atuação "a promoção da arte-educação; a difusão das manifestações folclóricas e populares da cultura brasileira; os centros e/ou conselhos tutelares, pastorais, comunitários e de direitos; as entidades recreativas, de esporte e lazer"; b) todo o Art. $3^{\circ}$ e $4^{\circ}$ relacionado à responsabilidade do Estado em assumir as políticas formativas, curriculares e salariais para o(a) educador(a) social; c) desconsidera a relação de gênero da profissão com a grande inserção de mulheres na profissão, não trazendo a denominação educadora social, na expressão "a profissão de educador social será exercida nos termos desta Lei”, isso não ocorria na redação do Projeto original. (BRASIL, 2013a)

Também o substitutivo, no Art. $4^{\circ}$, conservou a questão mais equivocada, que é reservar a atuação do (a) educador(a) social apenas em espaços não-escolares, desconhecendo vulnerabilidades e desfiliamentos sociais e escolares no âmbito desta (BRASIL, 2013a). Aliás, devemos lembrar que esse substitutivo não reconhece todos os espaços sociais e de educação não-escolar como possibilidade de atuação do educador social, por exemplo, o inciso XIII do Projeto original, que foi retirado e que trata da atuação em centros e conselhos tutelares não é lugar desse profissional, justamente aí onde se busca preservar o cumprimento das garantias legais a favor da criança e do adolescente, proposto no Estatuto da Criança e do Adolescente, o(a) educador(a), legalmente, não estará presente.

\section{As disputas em torno do projeto de Lei 5346/09: a ABRAPSOCIAL e AEESP}

Essa regulamentação não está sendo um processo sem conflitos, pelo contrário, demandas estão vindo à tona, todos disputam uma legislação que atenda aos seus interesses, já que o PL 5354/09 claramente atende, inicialmente, aos da Associação de Educadores e Educadoras do Estado do Ceará (AESC), o que não significa dizer que 
não seja de interesse de outras entidades e de educadores em todo o território nacional; mas as que claramente disputam esse projeto são a Associação Brasileira de Pedagogia Social (ABRAPSocial) e a Associação de Educadores e Educadoras Sociais de São Paulo (AEESP), que ora convergem, ora divergem suas ideias em torno do citado Projeto.

As duas principais ideias convergentes dessas associações se referem primeiro ao reconhecimento da necessidade de regulamentação das atividades de trabalho do(a) educador(a) social, a segunda diz respeito ao fato de que o PL 5354/09 não foi oriundo de uma discussão nacional envolvendo todos os educadores sociais, já que é o estado do Ceará que sai com essa proposta, apoiada pela AESC (AEESSP, 2013). Mas, ratificando, mesmo com muitas ausências pedagógicas, sociais e profissionais, percebemos que esse projeto dá conta, inicialmente, de questões cruciais da profissionalidade do educador social, pois só a possibilidade de regulamentar um campo profissional antes marginalizado é um grande avanço.

É claro que isso não invalida as críticas, que são necessárias para mobilizar o coletivo em busca de mudanças. Por exemplo, esse projeto, no que tange à formação do (a) educador(a) social, é meio silencioso, apenas diz que o Ministério da Educação é o responsável na formulação de políticas de formação. Essa é uma questão que pertence ao coletivo de educadores, pensar a concepção de currículo e formação mais adequada a partir de sua profissionalidade em cada modelo de educação social.

As divergências são que a ABRAPSocial defende: a) a regulamentação do campo da educação social e não os atributos necessários ao exercício da profissão, b) escolarização e formação específica e continuada para o(a) educador(a) social, c) abrangência das áreas de atuação profissional a partir do Estatuto da Criança e do Adolescente (Lei 8.069/90), da Lei de Execução Penal (Lei 7.210/84), da Lei de Diretrizes e Bases da Educação Nacional (Lei 9394/96), d) inclusão de elementos regulamentários da pedagogia social. (AEESSP, 2013)

A AEESSP defende: a) a regulamentação dos atributos cognitivos e profissionais referente à atividade de trabalho educativo social; b) a não escolarização mínima e formação continuada por não serem elementos preponderantes para a atuação profissional; c) restrição da área de atuação profissional, pois as atribuições contidas no ECA e na Lei de Execução Penal não se referem a(o) educador(a) social, mas a instituições e a um profissional chamado de orientador/aconselhador/tutor; d) não a incorporação de atributos referentes à pedagogia social que deve ser motivo de outro 
projeto de regulamentação. (AEESSP, 2013)

Em relação à primeira questão, observamos que a defesa pela regulamentação do campo e não dos atributos psicofísicos profissionais vai de encontro à tendência no Brasil que é de regulamentar as atividades de trabalho existentes em campo de conhecimento, como acontece com a profissão de turismólogo, de bibliotecário, engenheiro/arquiteto/engenheiro agrônomo, psicólogo, com exceção para a medicina que, embora busque regulamentar os atributos, na redação fala de regulamentação do exercício da medicina e não do médico (PL 7703/06 Lei do Ato Médico). Quando se regulamenta um campo profissional, termina por monopolizá-lo, legalizando-o para um único profissional e os outros, para atuarem, precisam do aval daquele. É o que estamos vendo com o PL do Ato Médico, muito criticado porque coloca a medicina como exclusividade do médico e todos os outros profissionais da saúde serão dependentes e a população refém do médico. (BRASIL, 2010)

Nesse sentido, regulamentar o campo da educação social, exclusivamente para o(a) educador(a) social, é não permitir que outros venham a atuar como líderes e pessoas de uma comunidade, entidades de classe, movimentos sociais, dentre outros. Todos devem ter o direito de também exercer atividades de trabalho, agrupar experiências e conhecimentos sobre a educação social.

Em relação à defesa pela escolarização e formação continuada como legitimadoras da atuação e carreira profissional, a ABRAPSocial tem razão, pois não se pode defender o exercício de uma profisssão tão importante sem uma formação de qualidade e crítica, que se inicia na escolarização fundamental, média e superior, passando por processos de qualificação permanente de maneira que o improviso educativo, muito reinante nesse exercício laboral, possa ser aniquilado, pois o improviso não qualifica a prática e nem a profissionalidade do(a) educador(a) social. No primeiro momento de certas atividades de trabalho que estão nascendo, que ainda não têm lastros sociais mais apurados, ações ainda em construção, se admitem pessoas sem escolarização e qualificação mínima para atuarem em um determinado tipo de trabalho, em particular os sociais, filantrópicos, assistenciais; mas com o avanço do trabalho, que incorpora experiências, conhecimentos, tecnologias educativas e sociais, é inadmissível a ideia de um profissional sem escolarização e qualificação profissional mais ampla. Agir, pensar e defender isso é retrocesso, é a total desvalorização das atividades de trabalho social e educativo do (a) educador (a) social.

A ideia hoje é que o (a) educador (a) seja um profissional crítico/crítica a partir da 
formação e da ação concreta nos problemas das populações vulneráveis/atendidas/desfiliadas. Não se concebe, nas profissões, a ausência da formação, que é um pré-requisito da regulamentação. Tirar essa profissão da marginalidade é caminhar pela formação qualitativa, para que o profissional goze de todos os direitos trabalhistas que a lei lhe garantir. Negar o direito à formação, em nome de ser uma profissão forjada nos movimentos sociais, é negar a possibilidade dele se emancipar e fazer o mesmo com as populações oprimidas, isso só interessa ao opressor.

Essa é uma conscientização ingênua da liderança da AEESP e que, subjacente a este pensamento, está aquele de negação das práxis revolucionárias de mudança radical do mundo. Associar-se a uma concepção de mundo realista é, no mínimo, negar a mudança que precisa ser operada na sociedade. Freire (1983, p. 48/9 - grifo do autor), ao analisar o papel do trabalhador social, diz que ele "não pode ser um homem neutro frente à desumanização [...] tem que fazer sua opção. Ou adere à mudança [...], ou fica a favor da permanência”. A mudança se dá no conhecimento da realidade que, não se reduz "ao nível da pura opinião (doxa) sobre a realidade. Faz-se necessário que a área da simples doxa alcance o longos (saber) e assim canalize para a percepção do ontos (essência da realidade)".

Em relação à abrangência das áreas de atuação das atividades de trabalho, incluindo muitos processos escolares e não escolares, é saudável a proposta da ABRAPSocial, reconhecendo outras possibilidades, pois não há dúvidas de que no campo da educação social estão outros profissionais, como educadores(as) do PETI, tutor judicial de adolescentes, educador popular das pastorais ou não, profissionais outros que trabalham com a ressocialização de adolescentes em privação temporária de liberdade, dentre outros. Estes, desde que executem atividades consideradas reeducativas, são educadores (as) sociais.

Aqui, temos uma questão que valeria refletir: é possível pensar em famílias ocupacionais para a atividade do educador social? Lembrando que, na Classificação Brasileira de Ocupações (CBO), essa atividade faz parte da família de trabalhadores de atenção, defesa e proteção a pessoas em situação de risco. Valeria um movimento nacional de luta a favor da criação, no $\mathrm{CBO}$, de outra família ocupacional para os educadores sociais, delimitando o campo de atuação e os atributos, pois, da forma que consta, não expressa o trabalho desse profissional e o que é pior, comete um erro grosseiro de excluir a escolarização.

Quanto à questão de inserir elementos referentes da pedagogia social no PL 
5346/09, a AEESP tem razão em defender uma institucionalidade diferente para a pedagogia social, pois existe uma diferença entre ser educador(a) e ser pedagogo(a), ambos existem independente um do outro, com funções claramente estabelecidas, se pensarmos que o PL 5346/09 visa a regulamentação dos atributos profissionais do(a) educador(a) social e que este, historicamente, atua nos meios sociais e educativos sem a exigência da graduação em pedagogia; logo, não há porque inserir algo relacionado a graduação em pedagogia social nesse Projeto, como forma de reconhecimento de uma atuação futura e carreira profissional, limitando outras possibilidades formativas.

Nesse sentido, a LDB 9394/96 e as Diretrizes Curriculares do Curso de Pedagogia, a Resolução CNE 01/2006, preveem a atuação do(a) pedagogo(a) geral na educação escolar e não-escolar (BRASIL, 1996; 2006). Talvez fosse interessante pensar na regulamentação profissional da pedagogia, embora ela já goze de muitas prerrogativas não vistas em outras profissões, como a presença maciça em todos os níveis de ensino, em todos os espaços onde ocorre educação, currículo nacionalmente sistematizado, dentre outras. Também é válido pensar na regulamentação da pedagogia social, mas, com certeza, o enfrentamento político e ideológico será uma briga homérica, mobilizando vários grupos que trabalham com outras pedagogias que também se sentirão no direito de reivindicar uma regulamentação própria. A saída desse impasse talvez fosse a regulamentação da pedagogia como profissão e nesse documento constar todas as possibilidades de atuação profissional, como a pedagogia social, pedagogia organizacional, pedagogia hospitalar e outras.

Nessa disputa político-ideológica de regulamentação da atividade de trabalho do(a) educador(a) social, tudo indica que quem saiu ganhando foi, claramente, a posição da ABRAPSocial quando do segundo substitutivo (SBT 2), proposto pela CTASP, após o diálogo com setores e pessoas interessadas nesse PL, não diz quem, mas pela exposto aqui fica evidente que a ABRAPSocial teve papel decisivo na reformulação do substitutivo do deputado Assis Melo. No título desse PL vem expresso a regulamentação da educação social como profissão, e não o contrário. $\mathrm{O}$ Art. $1^{\circ}$ diz que "a Educação Social é a profissão do educador social, pedagogo social e de profissionais com formação específica em Pedagogia Social, nos termos desta Lei”. Vejamos que prevalece a legalização do campo e não dos atributos psicofísicos da atividade de trabalho do(a) educador(a) social, incluiu o(a) pedagogo(a) social e outros, desde que possua a formação na área, isso implica em ampliar esse PL para atender a pedagogia social e, ao, mesmo tempo, inclui a formação superior como possibilidade de atuação, 
independentemente de ser ou não educador social forjado nos movimentos sociais, apenas a titulação acadêmica é suficiente. (BRASIL, 2013b)

A inclusão de pedagogos (as) sociais indica já uma hierarquização das funções no interior da educação social, que se torna, nesse PL, um campo de conhecimento e de profissionalidade, isso é evidente quando no Art. $3^{\circ}$ se estabelece como escolarização mínima para atuar no campo o ensino médio, não especificando se tratar de educação profissional. Isso implica dizer que haverá uma divisão das atividades no mercado de trabalho do (a) educador (a) e do pedagogo (a) social. A questão é saber quais as atividades de um e de outro e os atributos psicofísicos exigidos, já que esse Projeto só delimita, no Art. $4^{\circ}$, as funções e atribuições do (a) educador (a) social, especificando as áreas de atuação fora do âmbito escolar (BRASIL, 2013b).

Esse substitutivo mudou radicalmente a regulamentação das atividades de trabalho na educação social, imprimindo uma divisão interna ao campo a partir da ideia de domínios sociais, culturais e pedagógicos, claramente defendido pela ABRAPSocial. Há que se falar que a pedagogia social entra nesse PL apenas como profissão e não como ciência, teoria da educação social, pois o domínio epistemológico foi excluído dessas reformulações, indicando um sentido funcional a essa pedagogia.

\section{Conclusão}

Vimos, aqui, as tensões e intenções no percurso de legitimação da profissão de educação social, posta, decisivamente pelo PL 5346/09, que coloca novos desafios à profissionalização da educação e do(a) educador(a) social, bem como a construção de uma identidade socioprofissional, a exigência por uma escolarização e formação profissional de nível médio e superior; ao movimento social dos educadores, que agora devem continuar lutando para fazer valer a lei, quando esta for promulgada, as entidades de representação profissional quanto à defesa dos interesses dos seus associados, etc.

Nesse sentido, esse Projeto de Lei tem o grande mérito de estabelecer o debate nacional em torno da educação e dos educadores sociais. É um momento ímpar de visibilidade da história da educação social e dos movimentos sociais de educadores e educadoras sociais no Brasil. As disputas são necessárias e mostram que há disposição política e ideológica na defesa desse modelo de educação e profissão. Ambas são importantes tanto para o Estado, como sociedade civil, quanto para o mundo do trabalho e a academia. 
Isso é uma grande conquista dos (as) educadores (as) sociais, que estão vivendo uma situação histórica importante, almejada há muito pela velha guarda de educadores que atuaram nos anos de 1970-1990 e que não tinham garantias legais do exercício de sua profissão e nem tempo de se movimentar em busca dessa regulamentação, porque o trabalho com as populações vulneráveis estava começando. Tateavam nas práticas educativas, não tinham certeza de nada, apenas que faziam um trabalho social, um tanto perigoso, um tanto no improviso, com alguma ideia de pedagogia de Paulo Freire, mas que quando chegavam na prática concreta, querendo aplicar a teoria, viam que não era possível dadas as condições dos sujeitos que trabalhavam.

Eles queriam aplicar a teoria freireana, não entendiam que uma teoria pedagógica não se aplica, apenas serve de referência a uma nova realidade, pois a realidade social, cultural e pedagógica requer sempre um posicionamento dialético e a (re) construção de novos conhecimentos situados nessa realidade.

Esse movimento mostra avanços na profissionalidade do (a) educador (a) social, que começou, sem dúvida, na atuação com os meninos e meninas de rua. Nessa fase, por exemplo, quem não se lembra do trabalho no terceiro turno que ia das $19 \mathrm{~h}$ às $23 \mathrm{~h}$ ? E quanto aos lugares onde se concentravam os meninos (as) usuários (as) de maconha, cola e outras drogas? E o partilhamento de furtos que muitas vezes presenciavam? Quantos educadores não protegeram esses (as) meninos (as) da polícia, dos traficantes, dos transeuntes, dos padrastos e deles mesmos? E os medos diante de situações perigosas que colocavam em risco a integridade física e psíquica dos educadores? E qual o educador que não fazia o trabalho de assistência social, visitando a família desses meninos e meninas em lugares que muitos da coordenação do trabalho de rua não queriam ir por medo e preconceito? Quantos educadores e educadoras não foram vítimas de furtos e de intrigas dos (as) meninos (as)? Quantas afrontas sofridas pelos educandos? Quantas falsas testemunhas, inclusive relatos por parte dos (as) meninos (as) que estavam sendo assediados (as) pelos educadores/as?

Hoje, a frente de batalha é outra, mais difícil, como, por exemplo, o trabalho com crianças e adolescentes mortificados pelo crack, abusados sexualmente e ameaçados pelos traficantes; as ações educativas com os profissionais do sexo; com os moradores de rua; com as populações que brigam em prol da moradia, da terra, de tudo. No passado, não era fácil ser educador (a) social e no presente também não é. A diferença é que agora existe uma caminhada, um debate nacional, uma movimentação social e a possibilidade concreta de legitimação profissional da educação social, o que significa 
legalmente um reconhecimento social, graças, em parte, ao Projeto de Lei 5346/09.

\section{REFERÊNCIAS}

ASSOCIAÇÃO DE EDUCADORES E EDUCADORAS SOCIAIS DO ESTADO DE SÃO PAULO. Proposta de Emendas ao Projeto de Lei 5346/09. Leitura crítica da AEESSP às propostas da ABRAPSocial. Disponível em:

<https://docs.google.com/viewer?a=v\&pid=forums\&srcid=MDU4NDU0NzMwMTQy NTM3MDAzMjQBMDM1NTQzMjgzMjQ0MDQ3MDg1NzYBZmFmUXN1dF95aEl KATQBAXYy>. Acesso em: 08 fev. 2013.

BRASIL. Lei de Diretrizes e Bases da Educação Nacional. Ministério da Educação, $n^{\circ}$ 9.394, de 20 de dezembro de 1996. Estabelece as Diretrizes e Bases da Educação Nacional. Diário Oficial [da República Federativa do Brasil]. Brasília, 23 de dezembro de 1996. Seção I, pp. 27833.

BRASIL. Classificação Brasileira de Ocupações. Ministério do Trabalho e Emprego. Portaria $n^{\circ} 397$, de 09 de outubro de 2002. Aprova a Classificação Brasileira de Ocupações - CBO/2002. Disponível em:

<http://www.mtecbo.gov.br/cbosite/pages/legislacao.jsf>. Acesso em: 15 fev. 2011.

BRASIL. Projeto de Lei (PL) - 7703/2006. Dispõe sobre o exercício da medicina. Câmara dos Deputados, Projetos de leis e Outras Proposições. Brasília. Disponível em:

<http://www.camara.gov.br/proposicoesWeb/prop_mostrarintegra;jsessionid=3B753735 536494D5D6ED27590E66385D.node1 ? codteor=432204\&filename $=P L+7703 / 2006$ > Acesso em: 15 mar. 2010.

BRASIL. Projeto de Lei (PL) - 5346/2009. Dispõe sobre a criação da profissão de educador e educadora social e dá outras providências. Câmara dos Deputados, Projetos de leis e Outras Proposições. Brasília. Disponível em:

<http://www.camara.gov.br/proposicoesWeb/prop_mostrarintegra;jsessionid=79ACD13 4F482E205C0113905A393E710.node2? codteor $=661788 \&$ filename $=P L+5346 / 2009>$.

Acesso em: 11 nov. 2012.

BRASIL. Resolução do Conselho Nacional de Educação. Conselho Pleno, nº 01, de maio de 2006. Diretrizes Curriculares Nacionais para o Curs o de Graduação em Pedagogia, Licenciatura. Diário Oficial [da República Federativa do Brasil]. Brasília, 16 de maio de 2006. Seção I, pp. 11.

BRASIL. SBT 1 do Projeto de Lei (PL) - 5346/2009. Dispõe sobre a criação da profissão de educador e educadora social e dá outras providências. Câmara dos Deputados, Projetos de leis e Outras Proposições. CTASP. Brasília. Disponível em: <http://www.camara.gov.br/proposicoesWeb/prop_mostrarintegra?codteor=1069873\&fi lename=Tramitacao-SBT+1+CTASP+\%3D\%3E+PL+5346/2009>. Acesso em: 15 abr. 2013a.

BRASIL. SBT 2 do Projeto de Lei (PL) - 5346/2009. Dispõe sobre a criação da profissão de educador e educadora social e dá outras providências. Câmara dos 
Deputados, Projetos de leis e Outras Proposições. CTASP. Brasília. Disponível em: $<$ http://www.camara.gov.br/proposicoesWeb/prop_mostrarintegra?codteor=1086398\&fi lename $=$ Tramitacao-SBT+2+CTASP+\%3D\%3E+PL+5346/2009>. Acesso em: 14 maio $2013 b$.

CALIMAN, Geraldo. Pedagogia Social: seu potencial crítico e transformador. Revista de CIÊNCIAS da EDUCAÇÃO. UNISAL:Americana/SP, Ano XII, nº 23, p. 341-368, $2^{\circ}$ Semestre/2010.

CALIMAN, Geraldo. Pedagogia Social: Contribuições para a Evolução de um Conceito. In: SILVA, Roberto. et al. (Org.). Pedagogia Social: Contribuições para uma Teoria Geral da Educação Social. São Paulo: Expressão e Arte, 2011. p. 236-259.

CASTEL, Robert. Da indigência à exclusão, à desfiliação: precariedade do trabalho e vulnerabilidade relacional. In: LANCETTI, Antonio (Org.). Saudeloucura 4: grupos e coletivos. São Paulo: HUCITEC, 1994. p. 21-48.

CASTEL, Robert. A dinâmica dos processos de marginalização: a vulnerabilidade a desfiliação. Caderno do CRH, Salvador, no 26/27, p. 19-40, jan./dez., 1997.

CASTEL, Robert. As metamorfoses da questão social: uma crônica do salário. Petrópolis, RJ: Vozes, 1998.

CONTRERAS, José. Autonomia de Professores. São Paulo: Cortez, 2002.

DINIZ, Marli. Os donos do saber: profissões e monopólios profissionais. Rio de Janeiro: Revan,

2001.

DONZELOT, Jacques. A Polícia das famílias. Rio de Janeiro: Edições Graal, 1986.

DUBAR, Claude. A socialização: construção das identidades sociais e profissionais. Portugal: Porto

Editora, 2005.

FREIRE, Paulo. Educação e mudança. $8^{a}$ ed. Rio de janeiro: Paz e Terra, 1983.

FREIRE, Paulo. Pedagogia do oprimido. 17ª ed. Rio de Janeiro: Paz e Terra, 1997.

FREIRE, Paulo. Educação como prática de liberdade. Rio de janeiro: Paz e Terra, 2006.

GOFFMAN, Erving. Manicômios, prisões e conventos. São Paulo: Perspectiva, 2008.

GOHN, Maria da Glória. Educação não formal e o educador social. Atuação no desenvolvimento de projetos sociais. São Paulo: Cortez, 2010.

GRACIANI, Maria. Stela Santos. Pedagogia social de rua: análise e sistematização de uma experiência vivida. 4a . ed. São Paulo: Cortez, Instituto Paulo Freire, 2001 
LOUREIRO, Manuel; CASTELEIRO, Steven. A pedagogia social em Portugal. In. SOUZA NETO, João Clemente; SILVA, Roberto da; MOURA, Rogério (Org.). Pedagogia Social. São Paulo: Expressão e Arte, 2009.

LÓPEZ, Susana Torío. La pedagogía social em España. In. SOUZA NETO, João Clemente; SILVA, Roberto da; MOURA, Rogério (Org.). Pedagogia Social. São Paulo: Expressão e Arte, 2009.

MACHADO, Érico Ribas. Análises epistemológicas da pedagogia social em construção no Brasil. Disponível em:

<http://www.portalanpedsul.com.br/admin/uploads/2010/Educacao_e_Movimentos_Soc iais/Trabalho/02_37_04_ANALISES_EPISTEMOLOGICAS_DA_PEDAGOGIA_SOC IAL_EM_CONSTRUCAO_NO_BRASIL.PDF>. Acesso em: 08 dez. 2012.

MÉSZÁROS, István. A educação para além do capital. Trad. Isa Tavares. São Paulo: Boitempo, 2005.

OLIVEIRA, Walter Ferreira. Educação social de rua: as bases políticas e pedagógicas para uma educação popular. Porto Alegre: Artmed, 2004.

PAIVA, Jacyara Silva. Compreendendo as vivências e experiências produzidas na educação social de rua: desvelamentos pertinentes ao educador social de rua. 2011. 246f. Tese (Doutorado) - Universidade Federal do Espírito Santo, Vitória, ES, 2011.

PEREIRA, Antonio. A educação social de rua é uma práxis educativa? Revista Ciência da Educação. Unisal, Americana, SP, Ano XI, no 21, p. 481-500, $2^{\circ}$ semestre de 2009.

PEREIRA, Antonio. A Educação no Movimento Nacional de Meninos e Meninas de Rua (MNMMR): A Contribuição do Projeto Axé na legitimação da Pedagogia Social de Rua. Educação em Revista, Marília, v.12, n.2, p. 125-144, Jul.-Dez., 2011

SACRISTÁN, José Gimeno. Consciência e acção sobre a prática como libertação profissional dos professores. In: NÒVOA, Antonio. (org.). Profissão professor. Portugal: Porto, 1991.

SILVA, Roberto da. Visões e concepções necessárias a uma teoria geral da educação social. In. SILVA, Roberto da; SOUZA NETO, João Clemente; MOURA, Rogério; MACHADO, Evelcy Monteiro; CARO, Sueli. Pedagogia Social: contribuições para uma teoria geral da educação social. São Paulo: Expressão e Arte, 2011. p. 166-189

SOUZA NETO, João Clemente; SILVA, Roberto da; MOURA, Rogério (Org.). Pedagogia Social. São Paulo: Expressão e Arte, 2009.

TARDIF, Maurice; LESSARD, Claude; GAUTHIER, Clermont. Formação dos professores e contextos sociais. Porto, Portugal: Rés editora, 2001. 


\section{Como referenciar este artigo}

PEREIRA, Antônio. A profissionalidade do educador social frente a regulamentação profissional da educação social: as disputas em torno do projeto de Lei 5346/2009. Revista Ibero-Americana de Estudos em Educação, Araraquara/SP, v. 11, n. 3, p.1294-1317, 2016. Disponível em: <https://dx.doi.org/10.21723/riaee.v11.n3.6041>. EISSN: 1982-5587.

Submetido em: 07/07/2013

Aprovação final em: 04/07/2016 